\title{
Analysis and Improvement of the Rotary Percussion Drilling Tool in Oil Wells
}

\author{
Lingchao Xuan ${ }^{1, *}$, Zhichuan Guan ${ }^{2}$ and Huaigang $\mathrm{Hu}^{1}$ \\ ${ }^{1}$ School of Petroleum Engineering, China University of Petroleum Huadong, 266580 Qingdao, China
}

\begin{abstract}
Experience over the few years has proved that rotary percussion technology is an effective method to improve the rate of penetration in drilling petroleum wells. The drilling speed of the rotary percussion drilling is about forty percent larger than the common drilling. Research finds that rotary percussion drilling technology is still not mature in the aspects of high-efficiency, long-life, and low-cost. With the structure of deep wells becoming more complicated, designing new percussion tools with better impact performance and longer life has become the most remarkable research direction in drilling engineering. By analysing the shortcomings of existing percussion tools, a new idea of using the downhole motor driving the hammer piston to produce impulse force was proposed, and a novel rotary percussion drilling tool was made based on this principle. This new tool uses screw drill driving the hammer piston to rotate, meanwhile the hammer impact the susceptor to generate impulse pulse. In order to analyse the working state of the tool, the dynamic model of this percussion tool was established. Parameters of this novel drilling tool were tested by ground experiment, and the testing data and the computational value of dynamic model in a single impact process are very similar, so the model can be helpful in adjusting this tool's impact performances. The impulse force of this tool is about $0.2 \sim 0.5$ times to the bit weight; the impact frequency is the product of the rotary rate of the motor and the teeth number. The interval time of two impact processes is the same; the fluctuation of impact load is less than $10 \%$. Therefore, this rotary percussion drilling tool will be very helpful in improving the drilling speed in unconventional oil and gas reservoir. This tool's new principle and good performance can be helpful to the further development of rotary percussion drilling tool.
\end{abstract}

\section{Introduction}

The rotary percussion drilling tool is a kind of downhole power machine, which is generally connected to the drill bit. In drilling operation, the pressure gas or the drilling fluid pushes the piston up and down, and the piston hammers the joint of drill bit to produce impact load, then the drill bit breaks the rock into smaller pieces with the joint effect of the impact load and static bit weight [1]. This drilling method can improve the depth of drill bit forced into the rock, and generate large rock volume broken. The drilling speed of the rotary percussion drilling is forty percent larger than the common drilling [2-3]. With the stratigraphic structure of deep wells becoming more and more complicated, the safe and fast drilling operation becomes the first requirement of oilfield companies. So designing new percussion tools with better impact performance and longer life has become the most remarkable research direction in drilling engineering [4].

By analysing the rock broken principle upon impact cutting and the shortcomings of existing tools, this article designed a new rotary percussion tool. This new tool uses screw drill driving the hammer piston to rotate, meanwhile the hammer impact the susceptor to generate impulse pulse. The computational model of impulse load was established by dynamic theory, and the comprehensive performance of this tool was tested through ground experiments. Understanding the principle and working properties of this novel tool provides further improvement and promotion for the rotary percussion tools.

\section{Analysis of rotary percussion drilling technology}

In conventional drilling, the rock is cut under the action of the static bit weight and the cutting force. In rotary percussion drilling, the cutting teeth of the bit are affected by three kinds of acting force: the rotary cutting force, the static bit weight and the impact force [5]. The rock is broken up by impact failure and rotary cutting.

\subsection{The rock broken principle}

In the process of drill bit forced into the rock, the internal stress of formation rock reaches the compressive strength with the press of the bit weight and impact load, then the contact surfaces of the rock with cutting teeth are destructed gradually. The tiny striped cracks on the surface of rock forms and gradually become radial cracks [6]. As shown in Figure 1, when two major cracks fusion, it will form a long, narrow crushing area, finally generate many rock broken shaped like conches. With the bit rotating, the ridge between two adjacent pits will be cut off gradually by other teeth.

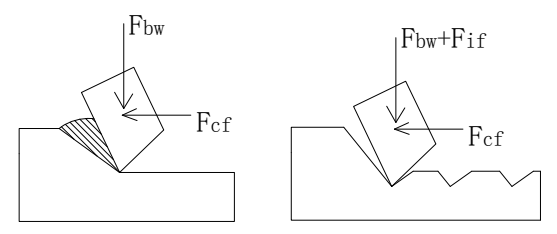

Figure 1. The rock broken principle of the rotary percussion technology. 


\subsection{The technical status}

The most common percussion tools in drilling operation include: hydro-efflux with valve type hammer, double acting jet-draw type hydraulic knocker, self-oscillating rotary impact drilling tool, and electric percussive-rotary drilling tool [7]. Although these hammer devices have many advantages, there is no large-scale application in oil drilling. Research finds that these tools used today have some common shortcomings and constraints. Such as, the impact tools have short working life and cannot match the life of one drill bit, and it will cause additional tripping operation; the impact force is too small in contrast with the bit weight, and impact energy is too little to generate rock broken effectively; some requirements for solid contents of drilling fluid are too rigorous, and it will increase the economic cost for oil exploration; finally, the impact parameters of some tools are hard to adjust in drilling complicated formations.

\subsection{The development direction}

The research shows that rotary percussion drilling technology is still not mature in the aspects of highefficiency, long-life, and low-cost. To improve the comprehensive performance of the downhole impactors needs more intensive study. The future development direction of the rotary percussion drilling tools include: developing the tools towards series and integration, and it can provide a comprehensive range of dimension to meet the various size of boreholes in unconventional reservoir; increasing the working life of the impact device, and designing special bit with shock resistance by changing teeth shape and the structure of blades, they can extend the working life of the impactor and bit; developing a

supplementary system for rotary percussion drilling, the system can select the type of impactor and optimum impact parameters suitable for different formations in drilling operation; designing some new rotary percussion drilling tools, and gradually improving the over-all properties of these novel tools.

\section{Design of a novel rotary percussion drilling tool}

Downhole motor is a dynamic drilling tool upon the power of drilling fluid. This stream pushes the rotor rotating, and the drive shaft transmits the torque onto the drill bit [8]. This tool has been widely used in common and directional drilling with advantages of stable performance and long life. The cam mechanism is used to change the direction of movement, and has been widely used in mechanical field [9]. By analysing the structure and characteristics of the screw drill and the cam mechanism, a novel rotary percussion tool powered by downhole motor was designed.

\subsection{The structure}

This new tool is made up of three parts: one part is a positive displacement motor upon the power of drilling fluid, the middle part is shaft and hard alloy bearings, and the end part is the percussion components, as shown in Figure 2. The percussion components have a disc spring, a hammer piston with teeth and a susceptor. The contact faces of percussion components are designed as the modified trapezoid curve, which is suitable for highspeed and light-load working condition. The susceptor is connected with the drill bit by tubing joint.

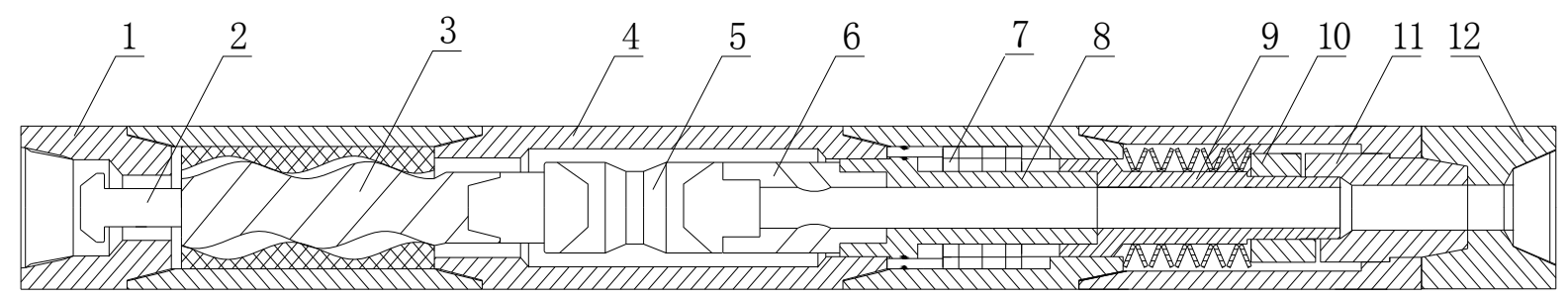

Figure 2. The Structure of the novel rotary percussion drilling tool.

1 - top joint; 2 -drop defence; 3 -stator and rotor; 4 -shell; 5 -versatile spindle; 6 - water valve;

7 -hard alloy bearings; 8 -shaft; 9 - disc spring; 10 - hammer piston; 11 -susceptor; 12 - bit joint.

\subsection{The working principle}

In the petroleum exploitation, the motor upon the power of drilling fluid drives the hammer piston rotating, meanwhile the hammer piston periodically hit the susceptor to produce impulsive pulse. The hammer piston climbs along the teeth of the susceptor and force the disc spring to compress and store the elastic energy at the same time. When the hammer piston reaches the prong of the susceptor, it will fall quickly with the disc spring thrusting, and finally the hammer piston hit the susceptor with high velocity. When the percussion process is finished, the downhole motor keeps the hammer piston rotating and climbing the raised and lowered face. The percussion process transforms the kinetic energy into the stress wave.

\section{The dynamic model of this percussion tool}

In order to analyse the working principle and working state of the novel rotary percussion drilling tool, a dynamic model of the impact process was established. 


\subsection{The calculation model of impact frequency}

In drilling operation, rock broken efficiency increases with the rotary speed increasing, but the bit rotary speed generally is $60 \sim 150 \mathrm{r} / \mathrm{min}$ limited by the surface equipment. The matching relationship between rotary speed and impact frequency affect rock broken efficiency. In actual application, the impact frequency is usually set as about $30 \mathrm{~Hz}$. This tool's impact frequency is decided by the rotary rate of positive displacement motor and the teeth of the hammer piston. The teeth structure of hammer piston was manufactured exactly the same by CNC machine tool.

$$
f=\frac{n_{\text {motor }} \cdot N_{\text {teeth }}}{60}
$$

\subsection{The calculation model of impact load}

In an instant of percussion process, the contact of the hammer piston and the susceptor is not full contact but partial contact, because the teeth surfaces of them are too complicated. The partial contact is like a spring with great stiffness between the hammer and the susceptor. This partial contact coefficient of percussion components usually is determined by ground test data.

Simplifying the profile of the hammer piston and susceptor, the percussion progress was studied by impact dynamic. The mathematical model of this tool was obtained:

$$
\left\{\begin{array}{c}
F=-M \frac{d v_{c}}{d t} \\
\frac{d F}{d t}=K_{C}\left(v_{c}-v_{z}\right) \\
F=m_{z} v_{z}
\end{array}\right.
$$

Simplifying these equations, the mathematical model of the impulse force of this new tool was obtained:

$$
F(t)=\frac{2 \delta v_{\max }}{\xi} e^{-\frac{K_{C}}{2 \delta t}} \operatorname{sh}\left(\frac{K_{C}}{2 \delta} t\right)
$$

Note: $\delta=A_{d} \sqrt{\rho E} ; \xi=\sqrt{1-\frac{4 \delta^{2}}{K_{C} M}}$

Different shapes and different contact surfaces of the piston will produce different stress wave. Generally, the hammer with elongated shape produces impact wave with low amplitude and long action time; the hammer with stubby shape produces impact wave with high amplitude and short action time. Changing the shape of the impact force has many methods, including adjusting the shape and section of the piston, adjusting the contact conditions of impact surfaces.

A further analysis of the function $F(\mathrm{t})$ was carried out, and the peak value of the novel tool's impact force was obtained:

$$
F_{\max }=v_{\max } \delta\left[\left(\frac{1-\xi}{1+\xi}\right)^{\frac{1}{2 \xi}} \frac{2}{\sqrt{1-\xi^{2}}}\right]
$$

\section{Testing experiment of this novel tool}

Ground experiment is the most accurate and effective method for measuring the impact force and impact energy of the tools. The main purposes of the experiment are: to test the tool's adaption to the large pump pressure, to find out the energy conversion law of the impactor [10]. The structure of the experimental device is shown as Figure 3.

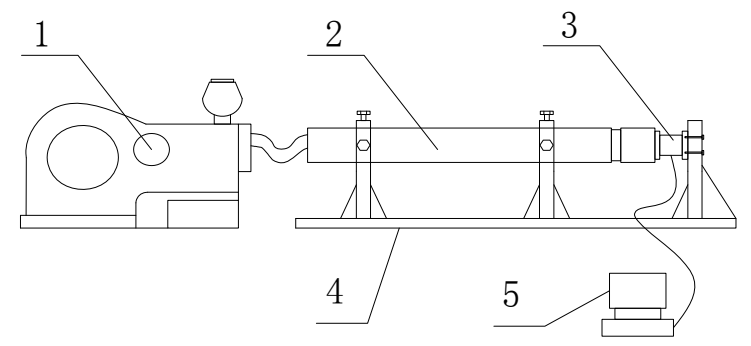

Figure 3. The Structure of the experimental device. 1 - mud pump; 2 -drilling tool; 3 -impact sensor; 4 -the base; 5 -acquisition system.

Changing working parameters of this tool several times, the properties with continuous impacting were testing. Meanwhile, mathematical model were calculated with the same working state. The spring force was set as $2.4 \mathrm{kN}$, the flow rate of the mud pump was $32 \mathrm{~L} / \mathrm{s}$.

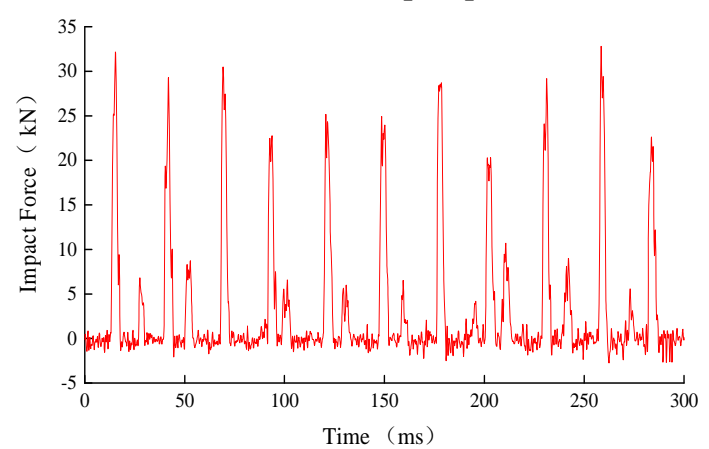

Figure 4. The measured value of continuous impact process.

As shown in Figure 4, the interval time of two impact processes is the same, which is determined by the stable rotary speed of downhole motor; the fluctuation of impact load is less than $10 \%$. This suggests that the impact process of this tool is obviously periodic and repeatable, because every process of the piston accelerated falling, the percussion process of hammer piston are exactly similar. The new tool's impact energy and frequency are set as the optimal value of the rotary percussion drilling technology.

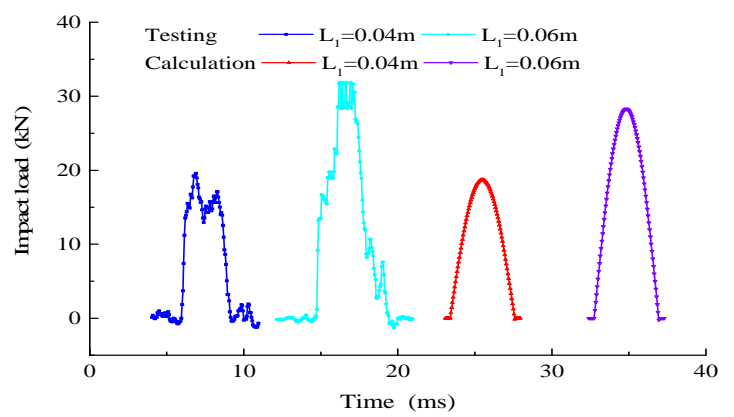

Figure 5. The calculation and measured value of single impact process. 
As shown in Figure 5, the testing data and the value of mathematical model are very similar in a single impact process. So the dynamic model of this tool's working process can be helpful in adjusting this tool's impact performances. Changing the stiffness coefficient and compressive force of disc spring, the impact load can be improved subsequently.

The action time of measured data is $3.9 \mathrm{~ms} \sim 4.5 \mathrm{~ms}$, the impact force is $0.2 \sim 0.5$ times to the bit weight, so it can provide a high drilling speed with rock broken up in volume. Therefore, this rotary percussion drilling tool will be very helpful in improving the drilling speed in unconventional oil and gas reservoir.

\section{Summary}

The research shows that rotary percussion drilling technology is still not mature in the aspects of highefficiency, long-life, and low-cost. To improve the comprehensive performance of the downhole impactors needs more intensive study.

A new idea of using the downhole motor driving the hammer piston to produce impulse force was proposed, and a novel rotary percussion drilling tool was made based on this principle. The interval time of two impact processes is the same; the fluctuation of impact load is less than $10 \%$. This suggests that the impact process of this tool is obviously periodic and repeatable, because every process of the piston falling and impacting is exactly similar.

The testing data and the computational value of mathematical model in a single impact process are very similar. So the calculation model can be helpful in adjusting this tool's impact performances. The new tool's impact energy and frequency are set as the optimal value of the rotary percussion drilling technology. Therefore, this rotary percussion drilling tool will be very helpful in improving the drilling speed in unconventional oil and gas reservoir.

\section{Acknowledgments}

This work was supported by the National Science and Technology Major Project Foundation of China "The safe \& fast drilling technologies for complicated formations in western China” (No. ZX05021).

\section{Nomenclature}

$n_{\text {motor }}$ - The rotary rate of downhole motor (r/s); $N_{\text {teeth }}$ The number of teeth, $M$-The piston mass (kg); $v_{\max }$ The final velocity of piston (m/s); $F$ - Impact load (N); $v_{\mathrm{C}}$ - The velocity of piston in impact $(\mathrm{m} / \mathrm{s}) ; v_{\mathrm{Z}}$ - The velocity of susceptor in impact $(\mathrm{m} / \mathrm{s}) ; K_{\mathrm{C}}$-Coefficient of contact surfaces $(\mathrm{N} / \mathrm{m}) ; l$-Spring of contact surfaces (m); $\delta$-The shock resistance of susceptor $(\mathrm{kg} / \mathrm{s}) ; f$ - Impact frequency $(\mathrm{Hz})$.

\section{References}

[1] Tao Xinghua. Effective measure for improving the penetration rate of deep well. Oil Drilling \& Production Technology. 23 (2001) 504-508.

[2] Wang Renjie. Hydraulic rotary percussion drilling. The Geological Publishing House, Beijing, China (1998).

[3] Tao Xinghua. 1996. Analysis of the characteristics of rotary percussion drilling. Drilling \& Production Technology. 19 (1996) 311-313.

[4] Liu Tianke. Application of self-oscillating rotary percussion drilling tools in Sheng li Oilfield. Oil Drilling \& Production Technology. 34((2012) 454456.

[5] Ni Hongjian, Han Laiju, Ma Qingming. Study on downhole vibration drilling tool induced by hydropulse. Oil Drilling \& Production Technology, 28 (2006) 215-220.

[6] Li Guohua, Bao Hongzhi, Tao Xinghua. Effects of drilling conditions on crushing rocks while rotary percussion drilling. Petroleum Drilling Techniques. 32 (2004) 204-207.

[7] Jian Zhijun, Zhang Wenhua, Liu Guohua. Current status and developing trend of research on hydraulic hole hammer for oil drilling. China Petroleum Machinery. 29 (2011) 1143-1146.

[8] Su Yinao. Research and application of positive displacement motor. Petroleum Industry Press. Beijing, China (2001).

[9] Liu Changqi, Liu Qingli, Cai Changwei. Practical design manual for cam mechanism. Science and Technology Press, Beijing, China (2001).

[10]Guan Zhichuan, Zhang Hongning, Liu Yongwang. Simulation of working characteristic of downhole hydraulically pulsed jet generator. Journal of China University of Petroleum (Edition of Natural Science). 39 (2001) 384-388. 